\title{
"Correlation Between Tooth Mineralization Using Cbet And Mp3 As A Diagnostic Tool For Assessment Of Skeletal Maturity - A Radiographic Study"
}

\author{
Dr. Sandesh S Pai ${ }^{1}$, *Dr. Jaya Singh ${ }^{2}$,Dr. Vinaya S Pai ${ }^{3}$,Dr. Vishwanath A.E ${ }^{4}$, \\ Dr. Suhas ${ }^{5}$,Dr. Anandu ${ }^{5}$ \\ ${ }^{I}$ Professor and HOD Dept. of Orthodontics Vydehi Institute of Dental Sciences \& Research Centre. \\ ${ }^{2} \mathrm{Pg}$ Student Dept. of HOD Orthodontics Vydehi Institute of Dental Sciences \& Research Centre. \\ ${ }^{3}$ HOD Dept. of Orthodontics Banglore Institute of Dental Sciences \& Research Centre. \\ ${ }^{4}$ Associate Professor Dept. of Orthodontics Vydehi Institute of Dental Sciences \& Research Centre. \\ ${ }^{5}$ Senior Lecturer Dept. of Orthodontics Vydehi Institute of Dental Sciences \& Research Centre. \\ Corresponding author: *Dr. Jaya Singh
}

\begin{abstract}
Background And Objectives- Treatment timing has a significant role in the outcome of all dentofacial orthopedic treatments for dentoskeletal disharmonies in growing patients. Dental maturation has been proposed to be a clinically useful diagnostic aid for the identification of individual skeletal maturation stages.

Aims: 1) To correlate dental calcification stages with MP3 stages in skeletal age estimation using CBCT of the left mandibular posterior teeth. 2) To determine whether dental calcification can be used as a first level diagnostic tool for assessment of skeletal maturity with MP3 stages.

Materials And Method - Study design included a total sample size of 30 including boys and girls, between the age group of 8 to 18 years visiting Vydehi Institute of Dental Sciences for orthodontic treatment. After analyzing the skeletal maturity through MP3 stages of each individual, it was compared with CBCT images Panoramic view and the respective stages of MP3 were correlated with CBCT Panoramic view for each tooth under investigation. The data was subjected to statistical analysis to determine the degree of correlation between the two maturation indices i.e. dental maturity and skeletal maturity with the help of Spearman Rank correlation coefficient and Sensitivity -Specificity analysis was done to identify the diagnostic ability of tooth mineralization stages to be used as a first level diagnostic tool for identification of skeletal maturity over other methods.

Results: 1) Significant correlation was seen between dental mineralization stages and MP3 method of skeletal maturation with $2^{\text {nd }}$ premolar stages being most reliable for skeletal maturity assessment.

2) The acceptability of the method to be used as first level Diagnostic tool is still not clear, though it can be used as a supplemental method along with principal method for skeletal maturity assessment.

Conclusion- Based on our study it is clear that second premolar has the highest significance level to rely on mineralization stage of the teeth to assess the skeletal maturity, and DMS method is more accurate in diagnosis of prepubertal individual than post pubertal individual with $2^{\text {nd }}$ molar having the highest sensitivity.
\end{abstract}

Keywords: Dental mineralisation stages, MP3 stages, CBCT- Panoramic View, prepubertal phase, postpubertal phase.

\section{Introduction}

Treatment timing has a significant role in the outcome of all dentofacial orthopedic treatments for dentoskeletal disharmonies in growing patients. For growth modification to be successful, it is absolutely essential that it start at right time. Optimal timing for treatment is different in various malocclusions. It is believed that treatment protocols aimed to modulate maxillary growth take advantage of treatment performed before the adolescent growth spurt, whereas modulation of mandibular growth is most effective during pubertal growth spurt ${ }^{1}$ Chronologic age is not a very reliable indicator to identify stages of growth because of individual variations in timing, velocity, and duration of growth. ${ }^{2}$

Dental maturation has been proposed to be a clinically useful diagnostic aid for the identification of individual skeletal maturation stages. Moreover, dental maturity assessment offers the advantage of being a simple procedure that can be carried out on panoramic radiographs that are routinely used for different purposes, and intraoral radiographs can be taken with minimal irradiation to the patient. Tooth emergence has also been investigated as a marker of skeletal maturity; however, this has been shown to be poorly correlated with individual skeletal maturity. The only previous diagnostic performance study showed that for early and 
intermediate mixed dentitions, satisfactory diagnostic accuracy is only seen for the identification of the prepubertal growth phase. ${ }^{9}$

Hence this study seeks to determine whether dental calcification can be used as a first level diagnostic tool for assessment of skeletal maturity, and correlating stages with MP3 stages in skeletal age estimation using $\mathrm{CBCT}$ of the mandibular posterior teeth. Thus the null hypothesis of the study is that dental calcification cannot be used as a first level diagnostic tool for assessment of skeletal maturity, and there is no statistically significant correlation between MP3 stages in skeletal age estimation and dental calcification stages.

\section{Materials And Method}

$>$ Study consisted of 30 subjects including boys and girls between age group 8 to 18 years who visited Vydehi Institute of Dental Sciences for orthodontic treatment with CBCT images of left mandibular posterior teeth and radiographs of the MP3 region .

$>$ Informed consent was obtained from all the patients.

\section{Inclusion Criteria}

$>30$ subjects (male and female ) within age range of $8-18$ years with Angle's Class I molar relationship and Class I skeletal relationship were selected.

> Subject should not have any history of orthodontic treatment, orthognathic or craniofacial surgery.

\section{Exclusion Criteria}

D Subjects with a history of congenital, developmental or hormonal disturbances that could affect their growth.

$>$ Subject with history of trauma or injury to the face leading to transposed teeth or injury to hand and wrist regions .

$>$ Subjects with history of extraction of any permanent teeth.

\section{Methodology}

Assessment of dental maturity using CBCT of mandibular posterior teeth(canine, firstpremolars, second premolars and second molars ) was carried out through calcification stages according to Demirjian et. al. from the CBCT images mandibular left posterior teeth. Patients were made to stand in Natural Head Position while taking CBCT image (Figure 1). Briefly, these stages are defined as follows (Figure 2).

\section{Stage D}

(1) Crown formation is complete down to the cementoenamel junction.

(2) The superior border of the pulp chamber in uniradicular teeth has a definite curved form and is concave towards the cervical region, and the projection of the pulp horns, if present, gives an outline shaped like the top of an umbrella.

(3) The beginning of root formation is seen in the form of spicule.

\section{Stage E}

(1) The wall of the pulp chambers form the straight lines, the continuity of which has broken by the pulp horns, which are larger than in the previous stage.

(2) The root length is less than the crown height.

\section{Stage F}

(1) The walls of pulp chambers form a more or less isosceles triangle, with the apex ending in a funnel shape.

(2) Root length is equal to or greater than crown height.

\section{Stage G}

(1)Wall of the root canal are parallel and its apical end is still partially open .

\section{Stage $\mathbf{H}$}

(1) The apical end of root canal is completely closed.

(2) The periodontal membrane has a uniform width around the root and the apex. Panoramic view of CBCT image (Figure 3) was analysed for the stage of mineralization seen with respect to canine, first premolar, second Premolar and second molar. The assessment of skeletal maturity will be carried out with the modified MP3 method described by Rajgopal and Kansal from the digital radiograph. Patients were asked to place the third finger and X-Ray tube is positioned perpendicular to the IOPAR film $(4,5)$.

This method comprises 6 stages, defined as follows. 
MP3-F stage: This stage is the start of the curve of pubertal growth spurt.

1) The epiphysis is as wide as metaphysis.

2) The end of epiphysis are tapered and rounded.

3) The metaphysis shows no undulation and the radiolucent gap (representing the cartilaginous epiphyseal growth plate) between the epiphysis and metaphysis is wide.

MP3-FG stage:This stage is the acceleration of the curve of the pubertal growth spurt.

1) The epiphysis is as wide as metaphysis.

2) A distinct medial and lateral border of the epiphysis forms a line of demarcation at a right angle to the distal border.

3) The metaphysis begins to show a slight undulation.

4) The radiolucent gap between the metaphysis and the epiphysis is wide.

MP3-G stage: This stage is the maximum point of the pubertal growth spurt.

1) The sides of the epiphysis have thickened and cap its metaphysis, forming sharp distal edge on atleast one side.

2) Marked undulations in the metaphysic give its a "cupid's bow" appearance.

3) The radiolucent gap between the epiphysis and the metaphysis is moderate.

MP3-H stage: This stage is the deceleration of the pubertal growth spurt.

1) Fusion of the epiphysis and the metaphysis begins.

2) Atleast one side of the epiphysis forms an obtuse angle to the distal border.

3) The epiphysis is beginning to narrow.

4) A slight convexity is seen under the central part of the metaphysis.

5) The typical "Cupid's bow" appearance of the metaphysis is absent but a slight undulation is distinctly present.

6) The radiolucent gap between the epiphysis and the metaphysis is narrower.

MP3-HI stage:This stage is the maturation of the curve of the pubertal growth spurt.

1)The superior surface of the epiphysis has a smooth concavity.

2)The metaphysis shows a smooth, convex surface, almost fitting into the reciprocal concavity of the epiphysis.

3)There is no undulations in metaphysis.

4)The radiolucent gap between the epiphysis and the metaphysis is insignificant.

MP3-I stage: This stage is the end of pubertal growth spurt.

1) Fusion of the epiphysis and metaphysis is complete.

2) There is no radiolucent gap between the metaphysis and the epiphysis.

3) Dense radiopaque epiphyseal line forms an integral part of the proximal portion of the middle phalanx.

After analyzing the skeletal maturity through MP3 stages of each individual, it is compared with CBCT images - Panaromic view and the respective stages of MP3 were correlated with CBCT Panaromic view for each tooth under investigation. The SPSS version 22, IBM., Corp was used for statistical analysis. The data will be subjected statistical analysis to determine the degree of correlation between the two maturation indices i.e. dental maturity and skeletal maturity with the help of Spearman Rank correlation coefficient and Sensitivity Specififcity analysis is done to identify the diagnostic ability of tooth mineralization stages to be used as a first level diagnostic tool for identification of skeletal maturity over other methods.

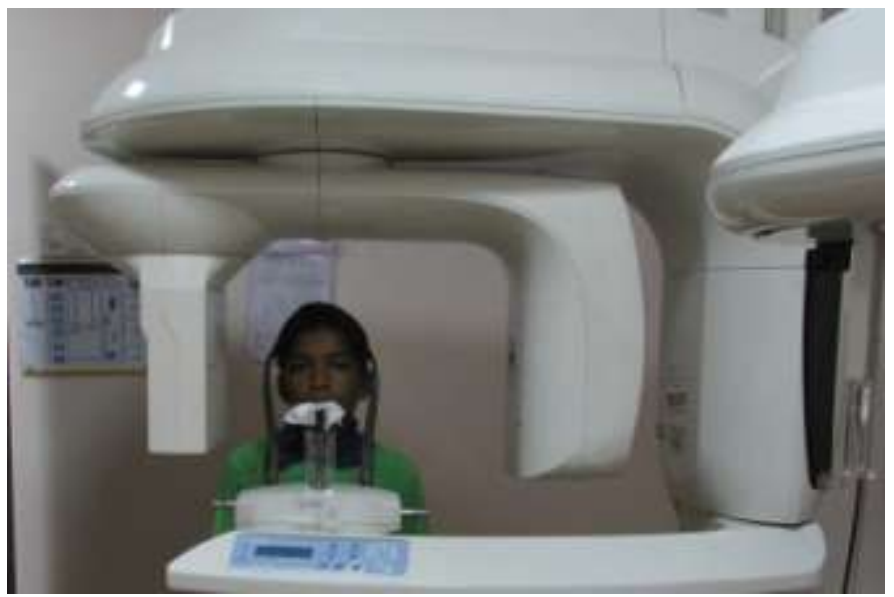

Figure 1: Cbct Machine And Patient In Natural Head Position 


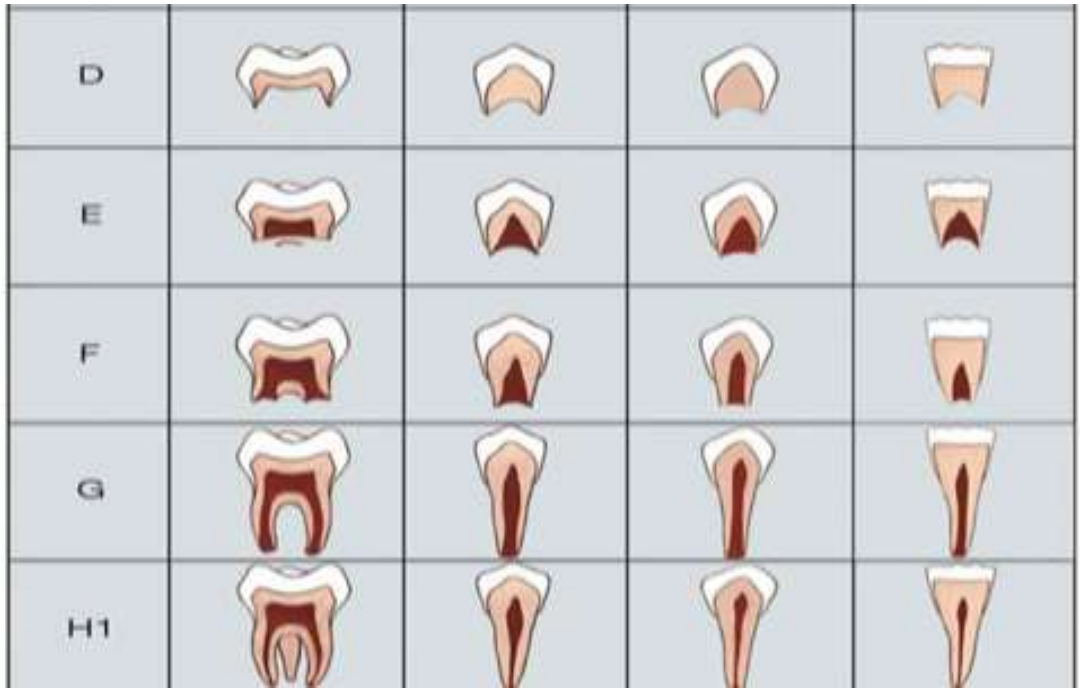

Figure 2: DEMIRIJIAN'S TOOTH MINERALIZATION INDEX

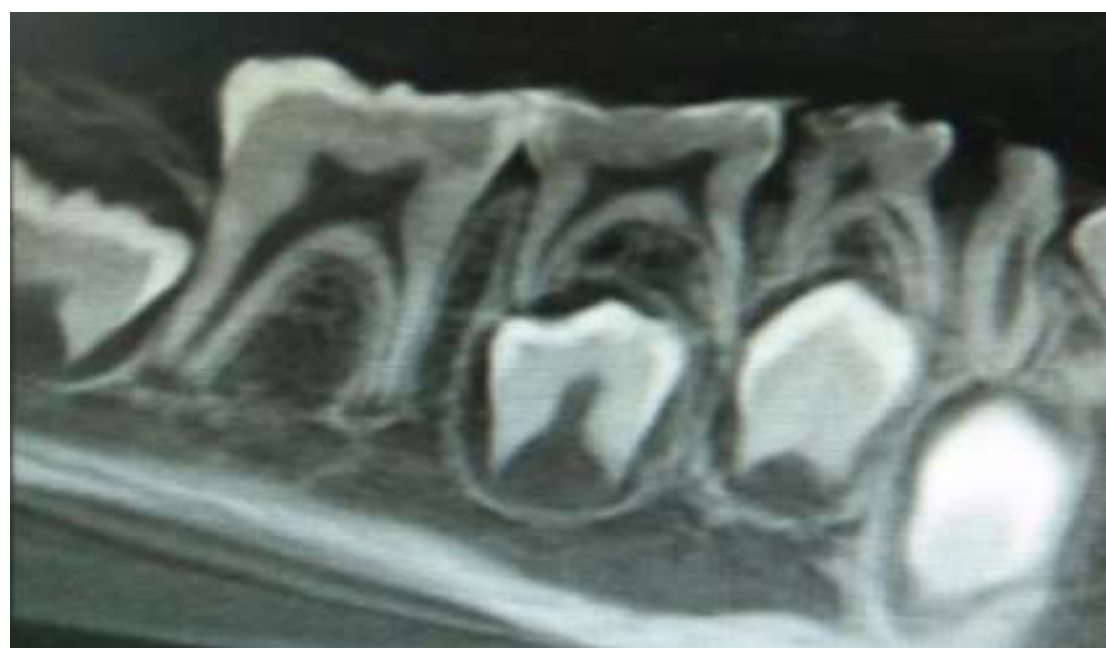

Figure 3: Cbct Image: Panoramic View Indicating Mineralisation In Relation To

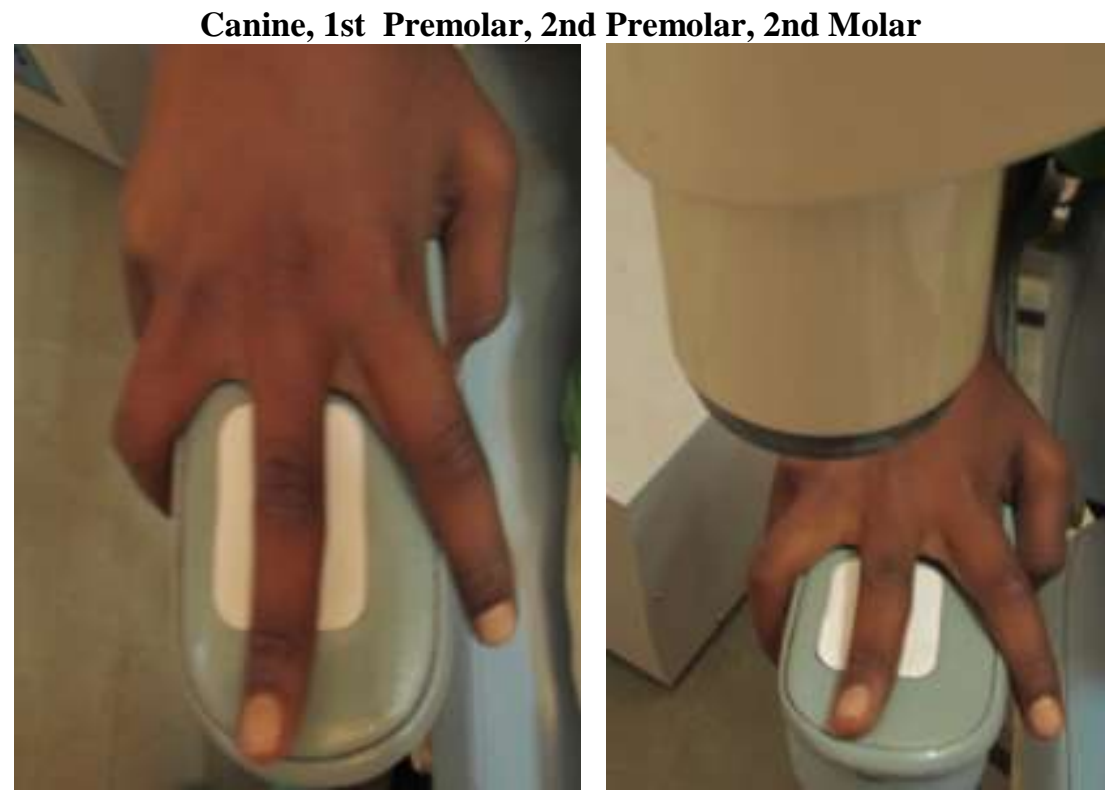

Figure 4: third finger middle phalanx placed on iopar film figure 5: $\mathrm{x}$ ray tube perpendicular to iopar film 


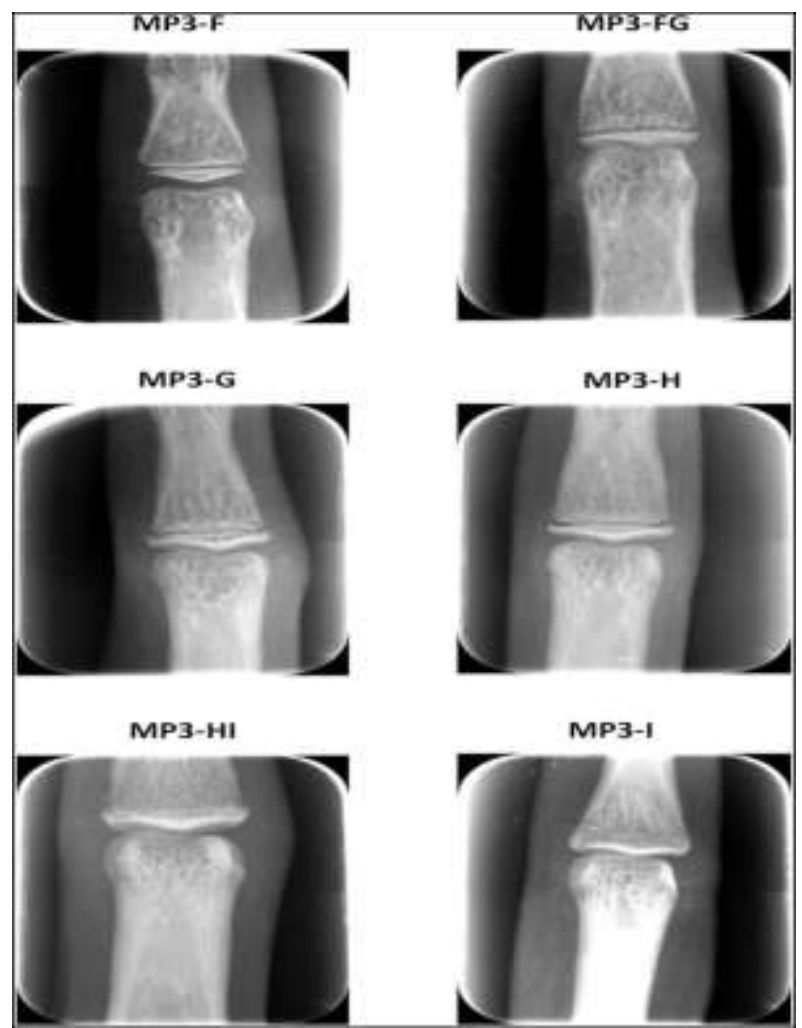

Figure 6: Developmental Stages Of Mp3 Radiographic View

\section{Results}

The purpose of the present study was to correlate dental calcification stages using CBCT of left mandibular posterior teeth with MP3 stages for skeletal age estimation and to determine the diagnostic ability of dental calcification stages for skeletal maturity. Group of 30 patients in the age group 8- 18 years who were visiting Vydehi Institute of Dental Sciences for Orthodontic treatment were randomly selected. CBCT images of left mandibular posterior teeth (canine, $1^{\text {st }}$ premolar, $2^{\text {nd }}$ premolar and $2^{\text {nd }}$ molar ) teeth were compared with IOPAR of MP3 region.

Table I shows demographic distribution in study subjects.

- In the study groups $40 \%$ of patients were in the age group of $8-10$ years.

- $36.7 \%$ of patients were under the age group of $11-13$ years.

- $23.3 \%$ of patients were in the age group of $14-16$ years.

- Genderwise, $46.7 \%$ of patients were females and $53.3 \%$ of patients were males in the study.

Table II shows relative distribution of dental maturation stages according to the skeletal maturation stages. To determine the degree of correlation between the 2 maturational indexes Spearman rank correlation coefficient was used. Spearman Rank Correlation Coefficient for dental maturation stage with MP3 stage ranges from 0.11 to 0.36 from $2^{\text {nd }}$ molar to 2 nd premolar respectively.

- Correlation coefficient for $2^{\text {nd }}$ premolar is showing borderline significance as $\mathrm{p}=0.05$.

- Whereas according to our study significance level for canine, $1^{\text {st }}$ premolar and second molar is questionable.

$\begin{array}{ll}\text { Teeth } & \text { Dms } \\ \text { Canine } & \text { Stage D } \\ & \text { Stage F } \\ & \text { Stage G } \\ 1^{\text {st }} \text { premolar } & \text { Stage D } \\ & \text { Stage H } \\ 2^{\text {nd }} \text { premolar } & \text { Stage D \& E } \\ 2^{\text {nd }} \text { molar } & \text { Stage D } \\ & \text { Stage G }\end{array}$

Mp3

$50 \%$ correlation with stage $\mathrm{F}$ and stage $\mathrm{G}$

Stage G correlation is $53.8 \%$.

Stage H correlation is $75 \%$.

Stage F correlation is $100 \%$.

Stage H with $100 \%$ correlation.

Stage F with $100 \%$ and $71.4 \%$ correlation

respectively.

Stage $\mathrm{G}$ with $66.7 \%$ correlation.

Stage H with $75 \%$ correlation. 
Teeth under investigation whose correlation is above $50 \%$ were considered to be reliable in the study when compared to MP3 method.

- From the above values, it is evident that canine Stage G of DMS is correlating with MP3 Stage H by $75 \%$, which signifies that canine Stage $\mathrm{G}$ is reliable in assessing the skeletal maturity of patients.

- Similarly, $1^{\text {st }}$ premolar, Stage D and H of DMS has $100 \%$ correlation with Stage F and H of MP3 respectively, which indicates that $1^{\text {st }}$ premolar stage D and H is as reliable as MP3 method for the assessment of skeletal maturity.

- $2^{\text {nd }}$ premolar, Stage D and Stage E of DMS has $100 \%$ and $71.4 \%$ correlation with Stage F of MP3 respectively, which signifies the reliability of Stage D and E of $2^{\text {nd }}$ premolar for skeletal maturity assessment.

- $2^{\text {nd }}$ molar Stage D and G of DMS is correlating by $66.7 \%$ and $75 \%$ with MP3 Stage G and H respectively, demonstrating $2^{\text {nd }}$ molar Stage D and Stage G reliability for the same.

Table III shows the pubertal phase indication by dental maturation stage and MP3 stages for canine, $1^{\text {st }}$ premolar, $2^{\text {nd }}$ premolar and $2^{\text {nd }}$ molar. Based on the MP3 method each stage can be categorized under prepubertal, post pubertal and circumpubertal individuals. According to the Index, MP3 F \& MP3 FG are prepubertal individuals, whereas MP3 H is circumpubertal, MP3 HI and MP3 I were post pubertal individuals, and it is compared with DMS, prepubertal and postpubertal, circumpubertal individuals based on secondary sexual characteristics of the individuals. Based on above method percentage distribution of prepubertal and postbubertal is calculated for 2 maturational indices.

Sensitivity and specificity analysis was done to assess the ability of each method for identifying the prepubertal and postpubertal individuals in study group.

- In our study dental maturity stages were correlated with MP3 stages for identification of pre pubertal phase and post pubertal phase.

- All the teeth under investigation, shows that DMS is more accurate in identification of prepubertal phase.

- Distribution for prepubertal phase for canine in DMS and MP3 is 70\% \& 40\% respectively and for postpubertal phase it is $30 \%$ \& $60 \%$ for DMS and MP3 respectively.

- Distribution for prepubertal phase for $1^{\text {st }}$ premolar in DMS and MP3 stage were $65 \%$ and $40 \%$ respectively, similarly post pubertal values are $35 \%$ and $60 \%$ respectively.

- $2^{\text {nd }}$ premolar values shows that prepubertal individuals were $60 \%$ and $40 \%$ and post pubertal individuals were $40 \%$ and $60 \%$ for DMS and MP3 respectively.

- Second molar has prepubertal individuals $85 \%$ and $40 \%$ and postpubertal individuals were $15 \%$ and $60 \%$ for DMS and MP3 respectively.

- According to our values, it is clear that DMS for Canine and $2^{\text {nd }}$ molar were most reliable for identifying prepubertal individuals in the study group which is almost $70 \%$ to $85 \%$.

Table IV, V, VI, VII shows sensitivity and specificity analysis in relation to canine, $1^{\text {st }}$ premolar, $2^{\text {nd }}$ premolar and $2^{\text {nd }}$ molar. Two groups of individual who are prepubertal and post pubertal according to MP3 method and other group of pre pubertal and post pubertal based on secondary sexual characteristics are included in sensitivity and specificity analysis for each tooth.

- Sensitivity for DMS in identifying individuals as prepubertal is $87.5 \%, 87.5 \%, 87.5 \%, 100 \%$ for canine, $1^{\text {st }}$ premolar, $2^{\text {nd }}$ premolar and $2^{\text {nd }}$ molar respectively compared to MP3 method .

- Based on the above result, test signifies that Dental Maturation Stage of $2^{\text {nd }}$ molar for prepuberty is almost as sensitive as MP3 method of skeletal maturity, followed by other teeth under investigation having almost same sensitivity for identification of prepubertal individual.

- Specificity for the DMS is $41.7 \%, 50 \%, 58.3 \%$ and $25 \%$ for canine, $1^{\text {st }}$ premolar, $2^{\text {nd }}$ premolar and $2^{\text {nd }}$ molar respectively compared to that of MP3 method used for assessment of postpubertal stages.

- Ability of DMS compared to MP 3 method in identifying post pubertal stages is almost $50 \%$ for $1^{\text {st }}$ premolar, $2^{\text {nd }}$ premolar and not of much significance for canine and $2^{\text {nd }} \operatorname{molar}(41.7 \% ; 25 \%)$.

- Based on the values obtained DMS method is not as reliable as MP3 method for identification of post pubertal individual.

Table VIII a shows the Positive Predictive Value and Negative Predictive Value; Positive Likelihood Ratio and Diagnostic Accuracy of dental maturation stages of canine, $1^{\text {st }}$ premolar, $2^{\text {nd }}$ premolar, and $2^{\text {nd }}$ molar in relation to MP3 stages.

- According to the present study Positive Predictive Values for canine, $1^{\text {st }}$ premolar, $2^{\text {nd }}$ premolar, and $2^{\text {nd }}$ molar are $58.3 \%, 58.3 \%, 58.3 \%$ and $47.1 \%$ respectively indicative of canine, $1^{\text {st }}$ and $2^{\text {nd }}$ premolar as good diagnostic ability for identification of true prebubertal. 
- Negative Predictive Values for canine $1^{\text {st }}$ premolar, $2^{\text {nd }}$ premolar, and $2^{\text {nd }}$ molar are $83.3 \%, 85.7 \%, 87.5 \%$, $100 \%$ respectively suggesting that second molar has maximum diagnostic ability for identification of true postpubertal individual .

- Positive Likelihood Ratio of DMS for canine, $1^{\text {st }}$ premolar, $2^{\text {nd }}$ premolar, and $2^{\text {nd }}$ molar are $1.50,1.75,2.10$, 1.33 indicative of the method as being good in diagnosis of the skeletal maturity, but to be used as a first level diagnostic aid Positive likelihood Ratio of the teeth under investigation should be more than 10 , therefore Dental Maturation Stages can be used as an adjunct with MP3 method to assess the skeletal maturity not as an principle method for the same.

- Diagnostic accuracy for canine, $1^{\text {st }}$ and $2^{\text {nd }}$ premolar $(0.60,0.65$ and 0.70$)$ is good whereas $2^{\text {nd }} \operatorname{molar}(0.55)$ is not satisfactory. Among the values $2^{\text {nd }}$ pre molar has the maximum diagnostic accuracy followed by $1^{\text {st }}$ pre molar, canine and the $2^{\text {nd }}$ molar. Therefore DMS method for $2^{\text {nd }}$ premolar in identifying the pubertal stages is satisfactory compared to other teeth under investigation.

Table IX is the master chart for the data collected in the present study. It includes 30 study subjects with their respective age, MP 3 stages of skeletal maturation, dental maturation stages of each teeth under investigation and pubertal status of patients based on seconday sexual characteristics of the patients. Based on our study it is clear that second premolar has the highest significance level to rely on mineralization stage of the teeth to assess the skeletal maturity, and DMS method is more accurate in diagnosis of prepubertal individual than post pubertal individual with $2^{\text {nd }}$ molar having the highest sensitivity.

Table I : Age And Gender Distribution In Study Subjects

\begin{tabular}{|c|l|c|c|} 
Variable & Categories & $\mathrm{N}$ & $\%$ \\
\hline \multirow{4}{*}{ Age Group } & $8-10 \mathrm{yrs}$ & 12 & $40.0 \%$ \\
\cline { 2 - 4 } & $11-13 \mathrm{yrs}$ & 11 & $36.7 \%$ \\
\cline { 2 - 4 } & $14-16 \mathrm{yrs}$ & 7 & $23.3 \%$ \\
\hline \multirow{3}{*}{ Gender } & Males & 14 & $53.3 \%$ \\
\cline { 2 - 4 } & Females & 16 & $46.7 \%$ \\
\hline
\end{tabular}

Table Ii: Relative Distribution Of The Dental Maturation Stages According To The Skeletal Maturation Stages

\begin{tabular}{|c|c|c|c|c|c|c|c|c|}
\hline \multicolumn{9}{|c|}{$(\mathrm{n}=30)$} \\
\hline \multirow[t]{2}{*}{ Tooth } & \multirow[t]{2}{*}{$\overline{\text { DMS }}$} & \multirow[t]{2}{*}{$\mathrm{n}$} & \multicolumn{4}{|c|}{ Mp3 } & \multirow[t]{2}{*}{ Rho } & \multirow[t]{2}{*}{ P-Value } \\
\hline & & & $\begin{array}{l}\text { Stg-F } \\
\end{array}$ & Stg-G & Stg-H & Stg-FG & & \\
\hline \multirow{5}{*}{ Canine } & Stg-D & 2 & $50.0 \%$ & $50.0 \%$ & .. & .. & \multirow[t]{5}{*}{0.18} & \multirow[t]{5}{*}{0.44} \\
\hline & Stg-E & 9 & $22.2 \%$ & $11.1 \%$ & $33.3 \%$ & $33.3 \%$ & & \\
\hline & Stg-F & 13 & $23.1 \%$ & $53.8 \%$ & $7.7 \%$ & $15.4 \%$ & & \\
\hline & Stg-G & 4 & .. & $25.0 \%$ & $75.0 \%$ & .. & & \\
\hline & Stg-H & 2 & .. & .. & $50.0 \%$ & $50.0 \%$ & & \\
\hline \multirow{5}{*}{ 1st pm } & Stg-D & 2 & $100.0 \%$ & .. &.. & .. & \multirow[t]{5}{*}{0.25} & \multirow[t]{5}{*}{0.18} \\
\hline & Stg-E & 6 & $50.0 \%$ & .. & $16.7 \%$ & $33.3 \%$ & & \\
\hline & Stg-F & 6 & $16.7 \%$ & $33.3 \%$ &.. & $50.0 \%$ & & \\
\hline & Stg-G & 14 & .. & $57.1 \%$ & $35.7 \%$ & $7.1 \%$ & & \\
\hline & Stg-H & 2 & ... & ... & $100.0 \%$ & .. & & \\
\hline \multirow{5}{*}{ 2nd pm } & Stg-D & 1 & $100.0 \%$ & .. &.. & .. & \multirow[t]{5}{*}{0.36} & \multirow[t]{5}{*}{$0.05^{*}$} \\
\hline & Stg-E & 7 & $71.4 \%$ & .. &.. & $28.6 \%$ & & \\
\hline & Stg-F & 7 & .. & $57.1 \%$ &.. & $42.9 \%$ & & \\
\hline & Stg-G & 13 & .. & $46.2 \%$ & $46.2 \%$ & $7.7 \%$ & & \\
\hline & Stg-H & 2 &.. & .. & $100.0 \%$ & .. & & \\
\hline \multirow{3}{*}{$\begin{array}{l}\text { 2nd } \\
\text { molar }\end{array}$} & Stg-D & 3 & $66.7 \%$ &.. & .. & $33.3 \%$ & \multirow[t]{3}{*}{0.11} & \multirow[t]{3}{*}{0.57} \\
\hline & Stg-E & 8 & $37.5 \%$ & $12.5 \%$ &. & $50.0 \%$ & & \\
\hline & Stg-F & 15 & $6.7 \%$ & $53.3 \%$ & $33.3 \%$ & $6.7 \%$ & & \\
\hline
\end{tabular}


“Correlation Between Tooth Mineralization Using Cbct And Mp3 As A Diagnostic....

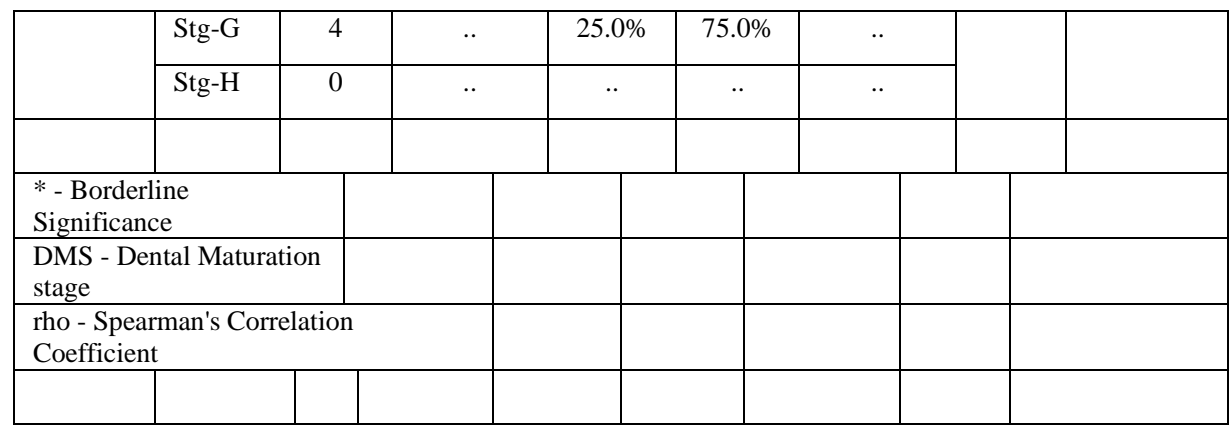

Table Iii: Pubertal Phase Indication By Dental Maturation Stage And Mp3 For Canine, $1^{\text {st }}$ Premolar, $2^{\text {nd }}$ Premolar, $2^{\text {nd }}$ Molar

\begin{tabular}{|l|c|c|}
\hline Pubertal Status & DMS & MP3 \\
\hline \multicolumn{3}{|c|}{ Canine } \\
\hline Pre-Pubertal & $70 \%$ & $40 \%$ \\
\hline Post-Pubertal & $30 \%$ & $60 \%$ \\
\hline \multicolumn{3}{|c|}{1 st PM } \\
\hline Pre-Pubertal & $65 \%$ & $40 \%$ \\
\hline Post-Pubertal & $35 \%$ & $60 \%$ \\
\hline \multicolumn{3}{|c|}{ 2nd PM } \\
\hline Pre-Pubertal & $60 \%$ & $40 \%$ \\
\hline Post-Pubertal & $40 \%$ & $60 \%$ \\
\hline \multicolumn{2}{|c|}{2 MLR } \\
\hline Pre-Pubertal & $85 \%$ & $40 \%$ \\
\hline Post-Pubertal & $15 \%$ & $60 \%$ \\
\hline
\end{tabular}

Table Iv: Sensitivity And Specificity Analysis For Canine Sensitivity \& Specificty Analysis

\begin{tabular}{|c|c|c|c|c|c|c|}
\hline \multirow[b]{3}{*}{ Tooth } & \multirow[b]{3}{*}{ Dms } & \multicolumn{4}{|c|}{ Sms [Mp3] } & \multirow[b]{3}{*}{ Total } \\
\hline & & \multicolumn{2}{|c|}{ Pre-Pubertal } & \multicolumn{2}{|c|}{ Post-Pubertal } & \\
\hline & & $\mathrm{N}$ & $\%$ & $\mathrm{~N}$ & $\%$ & \\
\hline \multirow[t]{3}{*}{ Canine } & Pre-Pubertal & $7 \mathrm{a}$ & $87.5 \%$ & $77_{b}$ & $58.3 \%$ & 14 \\
\hline & Post-Pubertal & $1_{\mathrm{c}}$ & $12.5 \%$ & $5_{d}$ & $41.7 \%$ & 6 \\
\hline & Total & 8 & $100 \%$ & 12 & $100 \%$ & 20 \\
\hline
\end{tabular}

Table V: Sensitivity And Specificity Analysis For $1^{\text {st }}$ Premolar

\begin{tabular}{|c|c|c|c|c|c|c|}
\hline \multirow[b]{3}{*}{ Tooth } & \multirow[b]{3}{*}{ DMS } & \multicolumn{4}{|c|}{ SMS [MP3] } & \multirow[b]{3}{*}{ Total } \\
\hline & & \multicolumn{2}{|c|}{ Pre-Pubertal } & \multicolumn{2}{|c|}{ Post-Pubertal } & \\
\hline & & $\mathrm{n}$ & $\%$ & $\mathrm{n}$ & $\%$ & \\
\hline \multirow[t]{3}{*}{ 1st PM } & Pre-Pubertal & $7_{\mathrm{a}}$ & $87.5 \%$ & $6_{\mathrm{b}}$ & $50.0 \%$ & 13 \\
\hline & Post-Pubertal & $1_{\mathrm{c}}$ & $12.5 \%$ & $6_{d}$ & $50.0 \%$ & 7 \\
\hline & Total & 8 & $100 \%$ & 12 & $100 \%$ & 20 \\
\hline
\end{tabular}

Table Vi: Sensitivity And Specificity Analysis For $2^{\text {nd }}$ Premolar

\begin{tabular}{|c|c|c|c|c|c|c|}
\hline \multirow[b]{3}{*}{ Tooth } & \multirow[b]{3}{*}{ DMS } & \multicolumn{4}{|c|}{ SMS [MP3] } & \multirow[b]{3}{*}{ Total } \\
\hline & & \multicolumn{2}{|c|}{ Pre-Pubertal } & \multicolumn{2}{|c|}{ Post-Pubertal } & \\
\hline & & $\mathrm{n}$ & $\%$ & $\mathrm{n}$ & $\%$ & \\
\hline \multirow[t]{3}{*}{ 2nd PM } & Pre-Pubertal & $7 \mathrm{a}$ & $87.5 \%$ & $5 \mathrm{~b}$ & $41.7 \%$ & 12 \\
\hline & Post-Pubertal & $1_{\mathrm{c}}$ & $12.5 \%$ & $7_{\mathrm{d}}$ & $58.3 \%$ & 8 \\
\hline & Total & 8 & $100 \%$ & 12 & $100 \%$ & 20 \\
\hline
\end{tabular}


“Correlation Between Tooth Mineralization Using Cbct And Mp3 As A Diagnostic....

Table Vii: Sensitivity And Specificity Analysis For $2^{\text {nd }}$ Molar

\begin{tabular}{|c|c|c|c|c|c|c|}
\hline \multirow[b]{3}{*}{ Tooth } & \multirow[b]{3}{*}{ DMS } & \multicolumn{4}{|c|}{ SMS [MP3] } & \multirow[b]{3}{*}{ Total } \\
\hline & & \multicolumn{2}{|c|}{ Pre-Pubertal } & \multicolumn{2}{|c|}{ Post-Pubertal } & \\
\hline & & $\mathrm{N}$ & $\%$ & $\mathrm{~N}$ & $\%$ & \\
\hline \multirow[t]{3}{*}{ 2nd Molar } & $\begin{array}{l}\text { Pre- } \\
\text { Pubertal }\end{array}$ & 8 a & $100 \%$ & $9 \mathrm{~b}$ & $75.0 \%$ & 17 \\
\hline & $\begin{array}{l}\text { Post- } \\
\text { Pubertal }\end{array}$ & $0_{\mathrm{c}}$ & $0 \%$ & $3_{d}$ & $25.0 \%$ & 3 \\
\hline & Total & 8 & $100 \%$ & 12 & $100 \%$ & 20 \\
\hline
\end{tabular}

Table viii: senstivity \& specificity; positive predictive value $\&$ negative predictive value; positive likelihood ratio $\&$ diagnostic accuracy of dental maturation stages for canine, $1^{\text {st }} \mathrm{pm}, 2^{\text {nd }} \mathrm{pm}, 2^{\text {nd }}$ molar in relation to $\mathrm{mp} 3$

\begin{tabular}{|l|c|c|c|c|c|c|}
\multicolumn{7}{|c|}{ stage. } \\
\hline \multicolumn{1}{|c|}{ Tooth } & Sn & Sp & PPV & NPV & PLR & AUC \\
\hline Canine & $87.5 \%$ & $41.7 \%$ & $58.3 \%$ & $83.3 \%$ & 1.50 & 0.60 \\
\hline 1st PM & $87.5 \%$ & $50.0 \%$ & $58.3 \%$ & $85.7 \%$ & 1.75 & 0.65 \\
\hline 2nd PM & $87.5 \%$ & $58.3 \%$ & $58.3 \%$ & $87.5 \%$ & 2.10 & 0.70 \\
\hline $\begin{array}{l}\text { 2nd } \\
\text { Molar }\end{array}$ & $100.0 \%$ & $25.0 \%$ & $47.1 \%$ & $100.0 \%$ & 1.33 & 0.55 \\
\hline
\end{tabular}

\section{Discussion}

The degree of skeletal development is a reflection of the degree of physiological maturation of a subject. The assessment of skeletal maturity is an important method in the evaluation, follow up, and timing of therapy in children with growth disorders, such as constitutional growth retardation and growth hormone deficiency, as well as endocrinological diseases, such as hypothyroidism, congenital adrenal hyperplasia, and precocious puberty. ${ }^{19}$

The present study was undertaken to correlate tooth mineralization using CBCT of left mandibular posterior teeth and radiographic image of MP3 region and determining whether dental calcification stages according to the method of Demirjian et al, can be used as a first level diagnostic tool for assessment of skeletal maturity. Highest level of correlation with MP3 system of skeletal maturity was seen for second premolars with correlation coefficient of 0.36 and significance of $\mathrm{P}=0.05$. It signifies that $2^{\text {nd }}$ premolar calcification stages can be used as an adjunct to various skeletal maturity method in identifying the growth status of patients. As in the above study canine stage $\mathrm{F}$ relates to onset of the accelerating growth spurt, our study canine stage $\mathrm{F}$ is correlating with Mp3 stage G by $53.8 \%$ which is the maximum point of pubertal growth spurt. The findings of this study indicate that tooth calcification stages might be clinically used as a maturity indicator of the pubertal growth period. Although we could not reach any conclusion regarding gender of patients and its relevance to correlation coefficient, it can be attributed to lower sample size in our study. However, further study is recommended with larger sample size, and future studies should address development of the canines and second molars and gender relation to tooth mineralization sequence.

With a versatile range of applications in the dental specialties, CBCT is becoming a valuable aid for diagnosis and treatment planning. In the present study we used CBCT images - Panaromic view of mandibular posterior teeth to asses the mineralization and correlate with Demirijian's tooth mineralization Index.

The result of present study shows that the Demirijians method of tooth calcification is correlated with MP3 method of maturity assessment with borderline significance seen only for second premolar. The diagnostic accuracy of the test is good but for being as a first level diagnostic tool positive likelihood ratio should be more than 10 , whereas in our study it is $1.50,1.75,2.10,1.33$ for canine, first premolar, second premolar, second molar respectively, which shows its a good diagnostic aid to use in conjuction with other methods. Among all the teeth under investigation second premolar showed highest diagnostic accuracy, followed by first premolar, then by the canine with second molars with least diagnostic accuracy compared to other teeth. CBCT scans increased the sensitivity of the test for individual teeth, whereas combination of all teeth it is not a very useful way compared to earlier studies done with panoramic radiographs. In future similar study with a larger sample size is required to prove the usefulness of the study as a first level diagnostic tool.

Thus, the Null hypothesis made in this study that dental calcification cannot be used as a first level diagnostic tool for assessment of skeletal maturity, and there is no statistically significant correlation between MP3 stages in skeletal age estimation and dental calcification stages is not acceptable as statistically significant values are obtained in our study, signifying the acceptance of the method. However, the possibility of it to be used as a first level diagnostic aid is still not very clear.

\section{Conclusion}

The results of the present study demonstrated that tooth mineralization assessment has significant correlation with MP3 method of skeletal maturity assessment. 


\section{The following conclusions were drawn from the study:}

$>$ Dental mineralization has significant correlation with skeletal maturation.

$>2^{\text {nd }}$ premolar mineralization stages are most reliable teeth to assess the skeletal maturity with maximum significance level compared to other teeth under investigation.

> Stage $\mathrm{D}$ of dental mineralization has maximum correlation for most of the teeth under investigation mainly $1^{\text {st }}$ premolars, $2^{\text {nd }}$ premolars and $2^{\text {nd }}$ molars with stage F of MP3 method.

$>$ DMS method is more accurate in diagnosis of prepubertal individuals mainly canine and $2^{\text {nd }}$ molar.

- As a result to start with orthopedic treatment we can rely on dental mineralization stages of canine and $2^{\text {nd }}$ molar as an adjunct with the principle method for prepubertal phase identification.

$>$ Even though sensitivity of the test is improved greatly by using CBCT images, the use of DMS as a first level diagnostic method cannot be proved effectively without further studies.

$>$ Based on our present study it is clear that dental mineralization, is a significant method which however needs more research in order to be used as a first level diagnostic method. It is advisable to do a similar study with a larger sample size to correlate Sexual dimorphism of the patients and its effects on mineralization sequence when compared to other skeletal maturity methods.

Hence, the null hypothesis that there is no significant correlation between tooth mineralization stages and MP3 method for skeletal maturity assessment is rejected, because there is significant correlation between the two methods with $2^{\text {nd }}$ premolar being the maximum, among all the teeth under investigation and to use the DMS method as first level dignostic method more research is required to reach any such conclusion.

\section{References}

[1]. Surendran S, Thomas E. Tooth mineralization stages as a diagnostic tool for assessment of skeletal maturity. Am J Orthod Dentofacial Orthop 2014; 145: 7-14

[2]. Beit P, Peltomaki T, Schatzle M, Signorelli L, Patcas R. Evaluating the agreement of skeletal age assessment based on hand-wrist and cervical vertebrae radiography. Am J Orthod Dentofacial Orthop 2013;144:838-47.

[3]. Krailassiri S, Anuwongnukroh N, Dechkunakorn S. Relationships Between Dental Calcification Stages and Skeletal Maturity Indicators in Thai Individuals. Angle Orthod 2002; 72:155-166.

[4]. Ishaq RAR, Soliman SAZ, Foda MY, Fayed MMS. Insulin - like growth factor 1: A biologic maturation indicator. Am J Orthod Dentofacial Orthop 2012; 142: 654-61.

[5]. Uysal T, Ramoglu SI, Basciftci FA, and Sari Z. Chronologic age and skeletal maturation of the cervical vertebrae and hand-wrist: Is there a relationship. Am J Orthod Dentofacial Orthop 2006; 130:622- 8.

[6]. Ruf S, Pancherz H. Frontal sinus development as an indicator for somatic maturity at puberty? Am J Orthod Dentofacial Orthop 1996; 110: 476-82.

[7]. Basaran G, Ozer T, Hamamci N. Cervical vertebral and dental maturity in Turkish subjects. Am J Orthod Dentofacial Orthop 2007;131:447.e13-447 .e20

[8]. Kumar S, Singla A, Sharma R, Virdi MS, Anupam A, Mittal B. Skeletal maturation evaluation using mandibular second molar calcification stages. Angle Orthod. 2012; 82:501-506.

[9]. Perinetti G, Contardo L, Gabrieli P, Baccetti T, Lenarda RD. Diagnostic performance of dental maturity for identification of skeletal maturation phase . Eur J Orthod. 2012; 34: 487-492.

[10]. Bjork A, Helm S. Prediction of the age of maximum pubertal growth in body height. Angle Orthod. $1967 ; 37: 134-143$.

[11]. Chertkow S, Fatti P. The Relationship Between Tooth Mineralization and Early Radiographic Evidence of The Ulnar Sesamoid. Angle Orthod. 1979; 49: 282- 288.

[12]. Chertkow S. Tooth mineralization as an indicator of the pubertal growth spurt. Angle Orthod. 1980; 80: 79- 91.

[13]. Engstrom C, Engstrom H, Sagne S. Lower Third Molar Development In Relation To Skeletal Maturity and Chronological Age. Angle Orthod. 1983; 53: 97 - 105.

[14]. Demirjian A, Buschang PH, Tanguay R, Patterson DK. Interrelationships among measures of somatic , skeletal, dental, and sexual maturity. Am J Orthod. 1985; 88: 433- 438.

[15]. Sierra AM. Assessment of Dental and Skeletal Maturity A New Approach. Angle Orthod .1987; $194-208$

[16]. Coutinho S, Buschang PH, Miranda F. Relationships between mandibular canine calcification stages and skeletal maturity. Am J Orthod Dentofac Orthop. 1993; 104: 262- 268.

[17]. Holtgrave EA, Kretschmer R, Muller R. Acceleration in dental development: fact or fiction. Eur J Orthod. 1997; 19: 703 - 710.

[18]. Nadler GL. Earlier dental maturation: Fact or Fiction? Angle Orthod .1998; 68: 535 - 538.

[19]. Uysal T, Sari Z, Ramoglu SL, Basciftci FA. Relationships between dental and skeletal maturity in turkish subjects. Angle Orthod. 2004; 74: $657-664$.

[20]. Ardakani F, Bashardoust N, Sheikhha M. The Accuracy of Dental Panoramic Radiography as an Indicator of Chronological Age In Iranian Individuals. J Forensic Odontostomatol. 2007; 25: $30-35$.

[21]. Sisman Y, Uysal T, Yagmur F, Ramoglu SL. Third Molar Development in Relation to Chronologic Age in Turkish Children and Young Adults. Angle Orthod. 2007; 77: 1040 - 1045.

[22]. Baccetti T, Franchi L, Lisa SD, Giutini V. Eruption of the maxillary canines in relation to skeletal maturity. Am J Orthod Dentofacial Orthop. 2008; 133: $748-751$.

[23]. Franchi L, Baccetti T, Toffol LD, Polimeni A, Cozza P. Phases of the dentition for the assessment of skeletal maturity: A diagnostic performance study. Am J Orthod Dentofacial Orthop. 2008; 133: 395 - 400

[24]. Cattaneo PM, Bloch CB, Calmar D, Hjortshoj M, Melsen B. Comparison between conventional and cone beam computed tomography - generated cephalograms. Am J Orthod Dentofacial Orthop. 2008; 134: 798 - 802.

[25]. Baumgaertel S, Palomo JM, Palomo L, Hans MG. Reliability and accuracy of cone beam computed tomography dental measurements. Am J Orthod Dentofacial Orthop.2009; 136: 19 -28.

[26]. Boonpitaksathit T, Hunt N, Roberts GJ, Petrie A, Lucas VS. Dental age assessment of adolescents and emerging adults in United Kingdom Caucasians using censored data for stage $\mathrm{H}$ of third molar roots. Eur J Orthod. 2011; 33: 503 - 508 
[27]. Sukhia RH, Fida M, Azam SI. Dental age table for a sample of Pakistani children. Eur J Orthod. 2012; $34: 77$ - 82.

[28]. Sandeep G, Sonia G. Comparative evaluation of permanent mandibular canine and second molar calcification stages for assessment of the skeletal maturity. Rwanda Med. J. 2013; 70: $12-18$.

[29]. Bagherpour A, Pousti M, Adelianfar E. Hand skeletal maturity and its correlation with mandibular dental development. J Clin Exp Dent. 2014; 6(3): e $275-279$.

[30]. Angelieri F, Franchi L, Cevidanes LHS, McNamara JA. Diagnostic performance of skeletal maturity for the assessment of midpalatal suture maturation. Am J Orthod Dentofacial Orthop. 2015; 148: 1010 - 1016.

[31]. Ravadgar M, Mirshekar A, Moudi E, Bijani A. Assosciation between teeth development in panoramic radiograph and skeletal maturity in lateral cephalogram. Avicenna J Dent Res. 2015; 7: 1 -8

[32]. Mustafa S, Raj AC, Anekar J, Divakar DD, Kheraif AAA, Ramakrishnaiah R, Khan AA, Alshahrani OA, Rai NP. Evaluation of dental and skeletal maturity using digital panoramic radiographs and digital cephalograms. Asian Biomed Journal. 2015; 9: 335 342.

[33]. Safer AN, Homel P, Chung DD. Lateral comparisons using Fishman's skeletal maturation assessment. Angle Orthod. 2015; 85: 408 -412 .

[34]. Arvindbhai SB, Ahammad YAR, Channamallappa RG, Pawar R, Phaphe S, Mane P. Radiographic Evaluation of Skeletal Maturity using Maxillary Canine And Mandibular Second Molar Calcification Stages in Western Maharashtra Population- A Retrospective Study. IJCMR. 2016; 3: $1750-1754$

[35]. Lopes LJ , Gamba TDO, Visconti MAPG, Ambrosano GMB, Neto FH, Freitas DQ. Utility of panoramic radiography for identification of the pubertal growth period. Am J Orthod Dentofacial Orthop. 2016; 149: 509 - 515

\footnotetext{
*Dr. Sandesh S Pai. "“Correlation Between Tooth Mineralization Using Cbct And Mp3 As A Diagnostic Tool For Assessment Of Skeletal Maturity - A Radiographic Study"." IOSR Journal of Dental and Medical Sciences (IOSR-JDMS) 16.7 (2017): 120-130. 